RESEARCH ArTICLE

Published October 19, 2020

\title{
The Structure of the Membrane Protein of SARS-CoV-2 Resembles The Sugar Transporter SEMISWEET
}

\section{AUTHOR}

Sunil Thomas

Lankenau Institute for Medical Research

Wynnewood, PA-19096, USA

E-mail: suntom2@gmail.com
DOI

DOI: $10.20411 /$ pai.v5i1.377

\section{SUGGESTED CITATION}

Thomas, S. The Structure of the Membrane Protein of SARS-CoV-2 Resembles the Sugar Transporter SemiSWEET. Pathogens and Immunity. 2020;5(1):342-363 PubMed PMID. doi: $\underline{10.20411 /}$ pai.v5i1.377

\section{ABSTRACT}

Background: Severe acute respiratory syndrome coronavirus 2 (SARS-CoV-2) is responsible for the disease COVID-19 that has decimated the health and economy of our planet. The virus causes the disease not only in people but also in companion and wild animals. People with diabetes are at risk of the disease. As yet we do not know why the virus has been highly successful in causing the pandemic within 3 months of its first report. The structural proteins of SARS include membrane glycoprotein $(M)$, envelope protein $(E)$, nucleocapsid protein $(N)$, and the spike protein $(S)$.

Methods: The structure and function of the most abundant structural protein of SARS-CoV-2, the membrane (M) glycoprotein, is not fully understood. Using in silico analyses we determined the structure and potential function of the M protein.

Results: The M protein of SARS-CoV-2 is $98.6 \%$ similar to the M protein of bat SARS-CoV, maintains $98.2 \%$ homology with pangolin SARS-CoV, and has $90 \%$ homology with the M protein of SARS-CoV; whereas, the similarity is only $38 \%$ with the M protein of MERS-CoV. In silico analyses showed that the M protein of SARS-CoV-2 has a triple helix bundle, forms a single 3-transmembrane domain, and is homologous to the prokaryotic sugar transport protein SemiSWEET. SemiSWEETs are related to the PQ-loop family whose members function as cargo receptors in vesicle transport, mediate movement of basic amino acids across lysosomal membranes, and are 
also involved in phospholipase flippase function.

Conclusions: The advantage and role of the $\mathrm{M}$ protein having a sugar transporter-like structure is not clearly understood. The M protein of SARS-CoV-2 interacts with S, E, and N protein. The $S$ protein of the virus is glycosylated. It could be hypothesized that the sugar transporter-like structure of the M protein influences glycosylation of the S protein. Endocytosis is critical for the internalization and maturation of RNA viruses, including SARS-CoV-2. Sucrose is involved in endosome and lysosome maturation and may also induce autophagy, pathways that help in the entry of the virus. Overall, it could be hypothesized that the SemiSWEET sugar transporter-like structure of the M protein may be involved in multiple functions that may aid in the rapid proliferation, replication, and immune evasion of the SARS-CoV-2 virus. Biological experiments would validate the presence and function of the SemiSWEET sugar transporter.

Key words: SARS-CoV-2, COVID-19, Coronavirus, Virus, Sugar transporter, SemiSWEET, Membrane glycoprotein, Pandemic.

\section{INTRODUCTION}

The coronavirus disease 2019 (COVID-19) is currently responsible for the pandemic that has decimated the health and economy of every country. COVID-19 is regarded as a respiratory disease that manifests with fever, cough, shortness of breath or difficulty breathing, chills, muscle pain, headache, sore throat, and loss of taste and smell. Other symptoms include diarrhea, nausea, and vomiting $[\underline{1}, 2]$. Many patients with the COVID-19 are asymptomatic but are able to transmit the virus to others $[\underline{3}, \underline{4}]$. The prolonged pandemic has resulted in social distancing, travel restrictions, decreased trade, high unemployment, commodity price decline, and financial stress that has impacted the global economy. COVID-19 disease is caused by the severe acute respiratory syndrome coronavirus 2 (SARS-CoV-2), a member of the betacoronavirus genus [ 5 ]. The disease has resulted in a mortality of $0.5 \%$ to $8.0 \%$. Several factors influenced the death rate in people with COVID-19. Age, health, and behavior of the population impacted the death rate due to COVID-19. Old people, people with underlying diseases such as diabetes, lung diseases (due to smoking), liver disease, cardiovascular disease, and obesity are more prone to death due to COVID-19. As yet, there are no effective drugs available for treatment of the disease nor vaccines available commercially to protect against the virus.

The major structural proteins of SARS-CoV-2 are spike (S), membrane (M), envelope (E), and the nucleocapsid $(\mathrm{N})$ proteins $[\underline{6}, \underline{7}]$. The spike protein of SARS-CoV-2 uses the host angiotensin-converting enzyme 2 (ACE2) as the entry receptor []. Hence, the research community has an interest in studying the spike protein for drug and vaccine development. Amraie et al [9] recently reported that the C-type lectin receptors CD209L/L-SIGN and CD209/DSIGN serve as alternative receptors for SARS-CoV-2 entry into human cells. The C-type lectin domain could function as a calcium-dependent glycan-recognition domain.

The most abundant structural protein of coronaviruses is the M glycoprotein; it spans the membrane bilayer, leaving a short NH2-terminal domain outside the virus and a long COOH terminus (cytoplasmic domain) inside the virion [10]. The M protein can bind to all other structural proteins. Binding with $\mathrm{M}$ protein helps to stabilize $\mathrm{N}$ proteins and promotes completion of viral assembly by stabilizing the N protein-RNA complex, inside the internal virion [11]. As the M pro- 
tein cooperates with the S protein, mutations may influence host cell attachment and entry of the viruses [12]. The $S$ protein of the virus is glycosylated and this modification may aid in immune evasion $[13,14]$. However, it is not known how the $S$ protein is glycosylated. The function of the $\mathrm{M}$ protein is also not fully understood.

Sugars Will Eventually be Exported Transporters (SWEETs) and SemiSWEETs are sugar transporters in eukaryotes and prokaryotes, respectively. SWEET proteins were first identified in plants as a novel family of sugar transporters that mediates the translocation of sugars across cell membranes [15-18]. Sugar transporters are essential for the maintenance of blood glucose levels in animals, nectar production, phloem loading, seed and pollen development in plants, and also in pathogen nutrition $[\underline{15}, \underline{18}]$. Engineering of SWEET mutants using genomic editing tools has been shown to mediate resistance to pathogens [19].

In eukaryotes, SWEET can discriminate and transport the uptake of mono and disaccharides across the plasma membrane by allowing solutes to permeate across biological membranes following a concentration gradient $[\underline{15}, \underline{19}, \underline{20}]$. Eukaryotic SWEETs are composed of 7 transmembrane helices (TMHs) that contain a pair of 3 transmembrane repeats, which are connected by an additional helix, while SemiSWEETs, the homologues of SWEETs in prokaryotes, contain 3 TMHs $[\underline{16}, \underline{21}]$. The human genome contains only 1 SWEET gene and may be involved in glucose transport [15].

The prokaryotic SemiSWEETs may be involved in the metabolism and transport of sugar synthesis. The SemiSWEETs of prokaryotes are more diverse than SWEETs in plants; they seldom have homologues sharing $>50 \%$ identity [17]. The limited number of SemiSWEET homologues suggest that they are not as important as the SWEETs in eukaryotes [1]].

The function and role of the M proteins of the SARS-CoV-2 during host infection is not clearly understood. Here, we report that the M proteins of SARS-CoV-2 are structurally similar to SemiSWEET sugar transport proteins of prokaryotes based on in silico analyses.

\section{Materials and Methods}

SARS-CoV-2 protein structure

The structural protein sequences of the SARS-CoV-2 were downloaded from the Pubmed (https://www.ncbi.nlm.nih.gov/pubmed) protein database. The structural proteins include Membrane protein (Accession No. QJA17755), Envelope protein (Accession No. QJA17754), Spike protein (Accession No. QHR63290), and Nucleocapsid protein (Accession No. QJC20758).

\section{Protein modeling}

Three-dimensional (3-D) structures of proteins provide valuable insights into their function on a molecular level and inform a broad spectrum of applications in life science research. A detailed description of the interactions of proteins and the overall quaternary structure is essential for a comprehensive understanding of biological systems, how protein complexes and networks operate, and how they could be modulated. SWISS-MODEL is a server that is used for 3-D structure prediction. SWISS-MODEL is the first fully automated protein homology modeling server and is updated continuously [22]. In our study, homology modeling was constructed using the SWISS-MODEL server (http://swissmodel.expasy.org/) and the iterative threading assembly 
refinement (I-TASSER) (https://zhanglab.ccmb.med.umich.edu/I-TASSER/) with default settings. The $\mathrm{M}$ protein sequence of SARS-CoV-2 was entered in FASTA format.

Residue-based diagrams of proteins, also called snake diagrams or protein plots, are 2-D representations of a protein sequence that contain information about properties such as secondary structure [23]. To determine a snake diagram model of a protein we used Protter (http://wlab. ethz.ch/protter). Protter is an interactive and customizable web-based application that enables the integration and visualization of both annotated and predicted protein sequence features together with experimental proteomic evidence for peptides and posttranslational modifications onto the transmembrane topology of a protein. It allows users to choose from numerous annotation sources, integrate their own proteomics data files, select the best-suited peptides for targeted quantitative proteomics applications, and export publication-quality illustrations [24].

\section{Sequence alignment}

Multiple sequence alignments (MSAs) are essential in most bioinformatics analyses that involve comparing homologous sequences [25]. ClustalW2 is a server for MSA that is also used for phylogenetic tree analysis. Multiple sequence alignments between the M protein of SARS-CoV-2 and the M proteins of SARS-CoV, bat SARS-CoV, pangolin SARS-CoV, and MERS-CoV, as well as SemiSWEET sequences from different microorganisms, were performed using the ClustalW2 server (http:/www.ebi.ac.uk/tools/msa/clustalW2/).

\section{RESULTS}

The $\mathrm{S}$ protein of SARS-CoV-2 binds to ACE2 receptors of the host for cell entry and may be a key target for drugs and vaccines. Hence, the S protein of SARS-CoV-2 virus is well characterized. The SARS-CoV-2 is one of the most successful viruses as it caused a pandemic within just 3 months of its first reported occurrence in Wuhan, China. As yet, we do not know why the virus has been successful in inducing a pandemic leading to millions of infections and thousands of deaths.

Three-dimensional protein structures provide valuable insights into the molecular basis of protein function [26]. Using in silico techniques the structure and potential function of the M protein of the SARS-CoV-2 virus was elucidated.

The structural protein sequence of the membrane protein (M) of SARS-CoV-2 is shown in Figure 1. The FASTA sequence of the M protein was entered into the SWISS-MODEL server and I-TASSER. Based on the sequence, the structure of the molecule was predicted as the bidirection-

\section{QJA17755.1 membrane glycoprotein [Severe acute respiratory syndrome coronavirus 2]}
1 madsngtitv eelkklleqw nlvigflflt wicllqfaya nrnrflyiik liflwllwpv 61 tlacfvlaav yrinwitggi aiamaclvgl mwlsyfiasf rlfartrsmw sfnpetnill 121 nvplhgtilt rplleselvi gavilrghlr iaghhlgrcd ikdlpkeitv atsrtlsyyk 181 Igasqrvagd sgfaaysryr ignykIntdh ssssdniall vq

Figure 1. The protein sequence of the M glycoprotein of SARS-CoV-2. The sequence was downloaded from the NCBI protein database. 


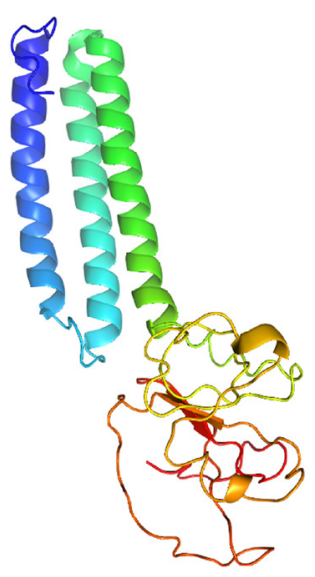

Figure 2. Predicted M protein structure of SARS-CoV-2 (ribbon diagram) using the software I-TASSER.

al sugar transporter SWEET2b. The ribbon representation model of the M protein as predicted using I-TASSER is shown in Figure 2.

The sugar transporter SWEETs of eukaryotes are generally composed of 7 transmembrane helices. Modeling proteins using residue-based diagrams (snake diagrams) helps us to understand their function. Hence, we used Protter to model the M protein.

The M glycoprotein is the most abundant envelope protein of SARS-CoV-2. In silico analyses of the M protein of SARS-CoV-2 using Protter demonstrated that it has a triple- helix bundle, and forms a single 3-transmembrane domain. In addition, the M glycoprotein has a short amino terminal domain outside the viral envelope and a long carboxy-terminal domain inside the viral envelope (Figure 3A). The SWISS-MODEL predicted the M glycoprotein as SWEET2b. However, the $M$ protein only has 3 transmembrane helices, not the 6 or 7 transmembrane helices which are observed in the SWEET sugar transporters of eukaryotes. Hence, the M glycoprotein structure of SARS-CoV-2 may be considered as SemiSWEET. To confirm accuracy of the study, we also modeled the E, N, and S proteins of SARS-CoV-2. The modeling showed that the E protein has a short outer amino terminal domain, a single helix, and a long inner carboxy-terminal domain (Figure 3B). The N protein had its entire structure inside the viral envelope (Figure 3C). Whereas, the S protein had the majority of its structure outside the viral envelope and a short carboxy-terminal domain inside the viral envelope (Figure 3D).

ClustalW2 was used to determine homology between M proteins of different coronaviruses. SARS-CoV-2 M protein has a sequence similarity of $98.6 \%$ with the M protein of bat SARS-CoV, 98.2\% homology with the pangolin SARS-CoV, $89.14 \%$ similarity with the M protein of SARS$\mathrm{CoV}$ and a sequence similarity of $38.36 \%$ with the M protein of MERS-CoV (Figures 4A-D). The MERS-CoV M protein had more homology with the sugar transporter SWEET (Table 1).

The SemiSWEET sugar transporters of prokaryotes are more diverse than the SWEET counterparts in plants. In the prokaryotes the SemiSWEET seldom share identity. We used ClustalW2 to determine sequence homology of the sugar transporters of multiple microorganisms. The 


\section{SARS-CoV-2 membrane protein (M)}

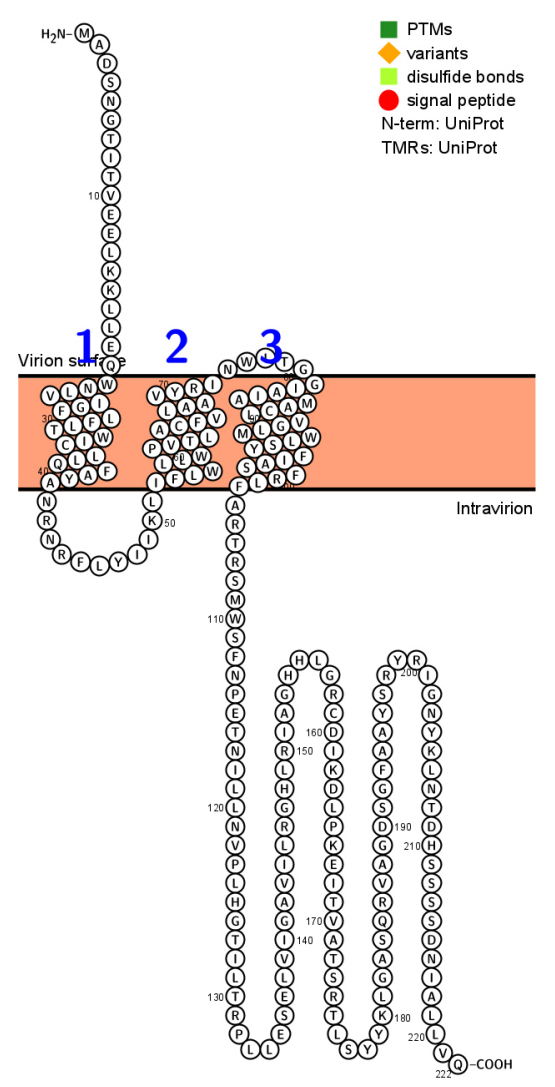

Figure 3. Membrane topology of proteins (snake diagrams) determined using Protter. (A) The membrane (M) glycoprotein of SARS-CoV-2 has a triple helix bundle and formed a single 3-transmembrane domain. (B) Snake diagram of envelope (E) protein, (C) nucleocapsid (N) protein, and (D) spike protein (S).

sequence of SemiSWEET of the M glycoprotein of SARS-CoV-2 had a similarity of $26 \%$ with the SemiSWEET of Rhizobiales and 20\% with Streptococcus pneumoniae demonstrating that the SemiSWEET of the SARS-CoV-2 may be highly conserved (Figures 5A, B).

\section{DISCUSSION}

The COVID-19 pandemic caused by the coronavirus SARS-CoV-2 is spreading at an alarming rate and has resulted in an unprecedented health emergency all over the world [27]. The rapid spread of SARS-CoV-2 justifies the global effort to identify effective preventive strategies and optimal medical management [28].

As yet there are no effective vaccines to protect against COVID-19 nor effective approved drugs to treat patients with the disease. The development of antivirals is an urgent priority to combat the disease [27]. In the absence of effective and safe vaccines or antivirals to control the disease, strategies for mitigating the burden of the pandemic are focused on non-pharmaceutical interventions, such as social-distancing, contact-tracing, quarantine, isolation, and the use of face masks in public [29]. 


\section{SARS-CoV-2 envelope protein (E)}

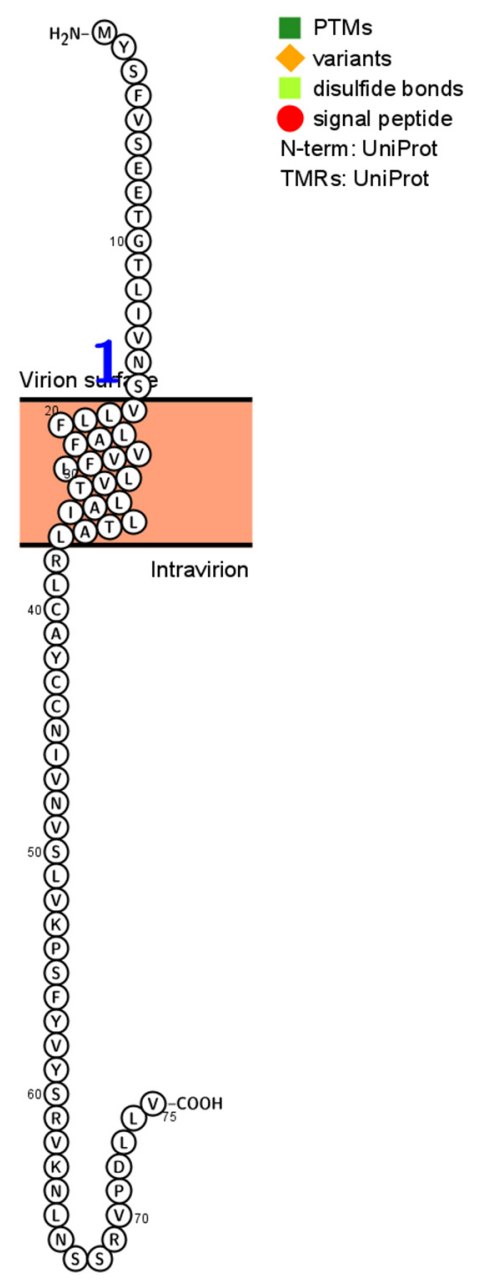

Figure 3B.

The primary route of transmission of COVID-19 is likely via respiratory droplets and is known to be transmissible from pre-symptomatic and asymptomatic individuals [ $\underline{30}]$. Infected people spread viral particles during talking, breathing, coughing, or sneezing. Such viral particles are known to be encapsulated in globs of mucus, saliva, and water, and the fate/behavior of globs in the environment depends on the size of the globs [31]. Studies show that SARS-CoV-2 can be detected in the air and remain viable 3 hours after aerosolization. The weight of combined evidence supports airborne precautions for the occupational health and safety of health workers treating patients with COVID-19 [르].

It has been shown that wearing a mask reduces the contact transmissibility by reducing transmission of infected droplets in both laboratory and clinical contexts. Public mask- wearing is most effective at reducing the spread of the virus when compliance is high. The decreased transmissibility could substantially reduce the death toll and economic impact while the cost of the intervention is low [이]. The community-wide benefits are likely to be greatest when face masks are 


\section{SARS-CoV-2 nucleocapsid protein (N)}

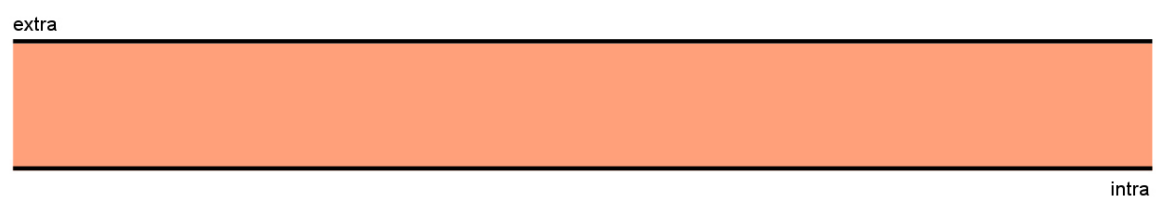

Figure 3C.

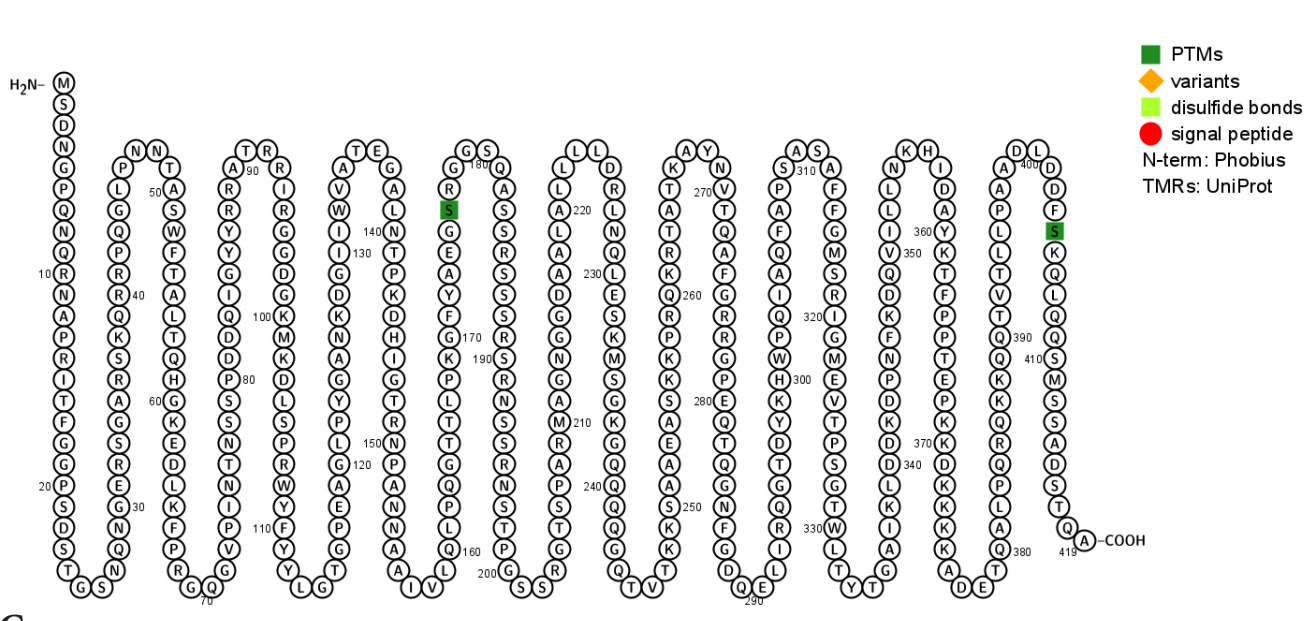

SARS-CoV-2 spike protein (S)

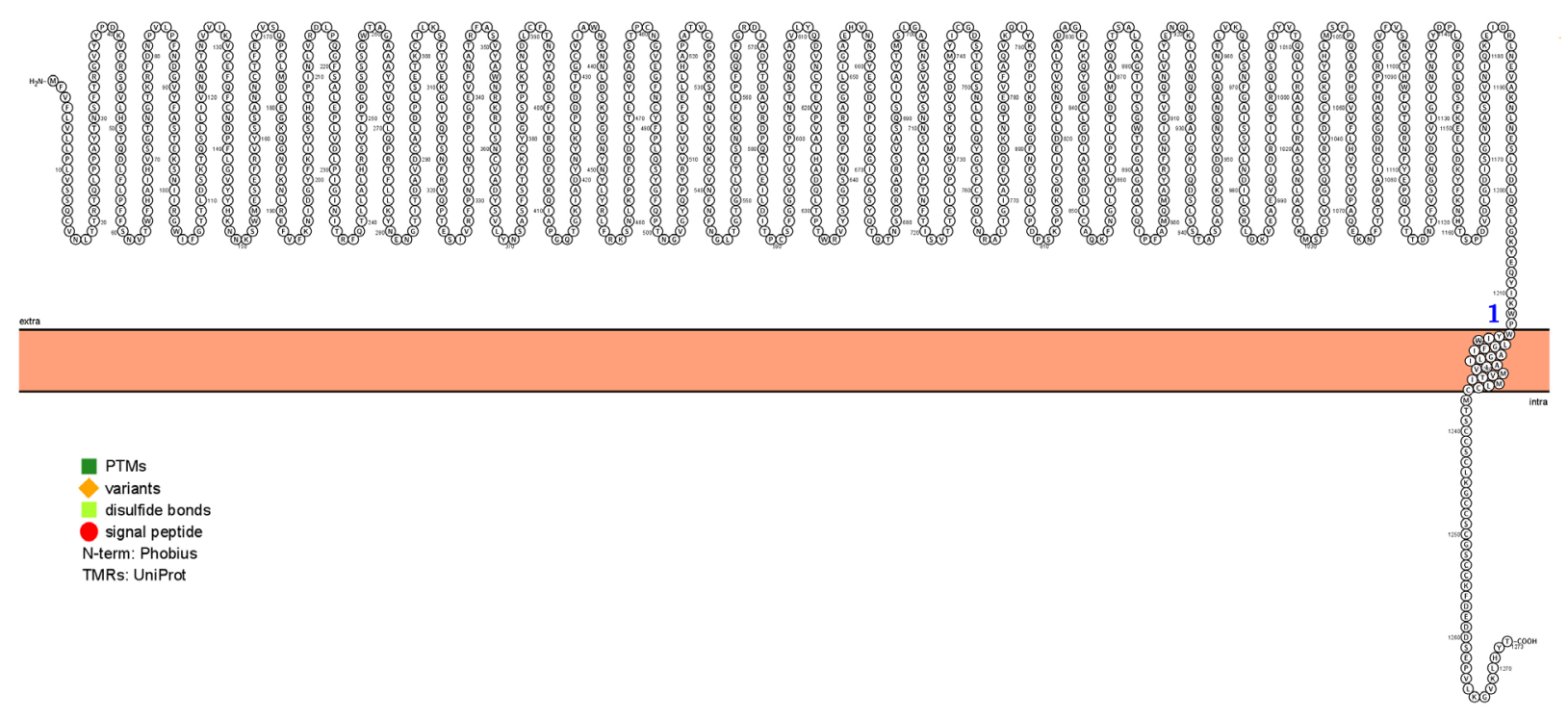

Figure 3D. 
Table 1. Homology of the M protein of SARS-CoV-2 with the M protein of other coronaviruses and the sugar transporter SWEET

\begin{tabular}{|l|c|c|}
\hline \multicolumn{1}{|c|}{ Membrane Protein } & $\begin{array}{c}\text { Membrane protein identity } \\
\text { (with SARS-CoV-2) }\end{array}$ & $\begin{array}{c}\text { Bidirectional sugar transporter } \\
\text { SWEET identity }\end{array}$ \\
\hline SARS-CoV-2 & 100 & 14.3 \\
\hline Bat SARS-CoV & 98.64 & 14.3 \\
\hline Pangolin SARS-CoV & 98.2 & 14.3 \\
\hline SARS-CoV & 89.14 & 14.3 \\
\hline MERS-CoV & 38.36 & 20.0 \\
\hline
\end{tabular}

CLUSTAL 0(1.2.4) multiple sequence alignment

\begin{tabular}{|c|c|c|}
\hline QJA17755.1 & MADSNGTITVEELKKLLEQWNLVIGFLFLTWICLLQFAYANRNRFLYIIKLIFLWLLWPV & 60 \\
\hline QHR63303.1 & $\begin{array}{r}\text {-MADNGTITVEELKKLLEQWNLVIGFLFLTWICLLQFAYANRNRFLYIIKLIFLWLLWPV } \\
. * * * * * * * * * * * * * * * * * * * * * * * * * * * * * * * * * * * * * * * * * * * * * * * * * * * * * * * *\end{array}$ & 59 \\
\hline QJA17755.1 & TLACFVLAAVYRINWITGGIAIAMACLVGLMWLSYFIASFRLFARTRSMWSFNPETNILL & 120 \\
\hline QHR63303.1 & $\begin{array}{l}\text { TLACFVLAAVYRINWITGGIAIAMACLVGLMWLSYFIASFRLFARTRSMWSFNPETNILL } \\
* * * * * * * * * * * * * * * * * * * * * * * * * * * * * * * * * * * * * * * * * * * * * * * * * * * * * * * * * * * *\end{array}$ & 119 \\
\hline QJA17755.1 & NVPLHGTILTRPLLESELVIGAVILRGHLRIAGHHLGRCDIKDLPKEITVATSRTLSYYK & 180 \\
\hline QHR63303.1 & $\begin{array}{l}\text { NVPLHGTILTRPLLESELVIGAVILRGHLRIAGHHLGRCDIKDLPKEITVATSRTLSYYK } \\
* * * * * * * * * * * * * * * * * * * * * * * * * * * * * * * * * * * * * * * * * * * * * * * * * * * * * * * *\end{array}$ & 179 \\
\hline QJA17755.1 & LGASQRVAGDSGFAAYSRYRIGNYKLNTDHSSSSDNIALLVQ & \\
\hline QHR63303.1 & $\begin{array}{l}\text { LGASQRVAGDSGFAAYSRYRIGNYKLNTDHSSSSDNIALLVQ } \\
* * * * * * * * * * * * * * * * * * * * * * * * * * * * * * * * * * * * * * *\end{array}$ & \\
\hline
\end{tabular}

QJA17755.1: Membrane protein SARS-CoV-2

QHR63303.1: Membrane protein [Bat SARS CoV RaTG13]

Percent identity: 98.64

Figure 4. Protein sequences were aligned using ClustalW. Comparison of protein sequence of the $M$ protein of SARS-COV-2 with (A) M protein of Bat SARS-CoV, (B) M protein of pangolin SARS-CoV, (C) $\mathrm{M}$ protein of SARS-CoV, and (D) MERS-CoV. 
CLUSTAL O(1.2.4) multiple sequence alignment

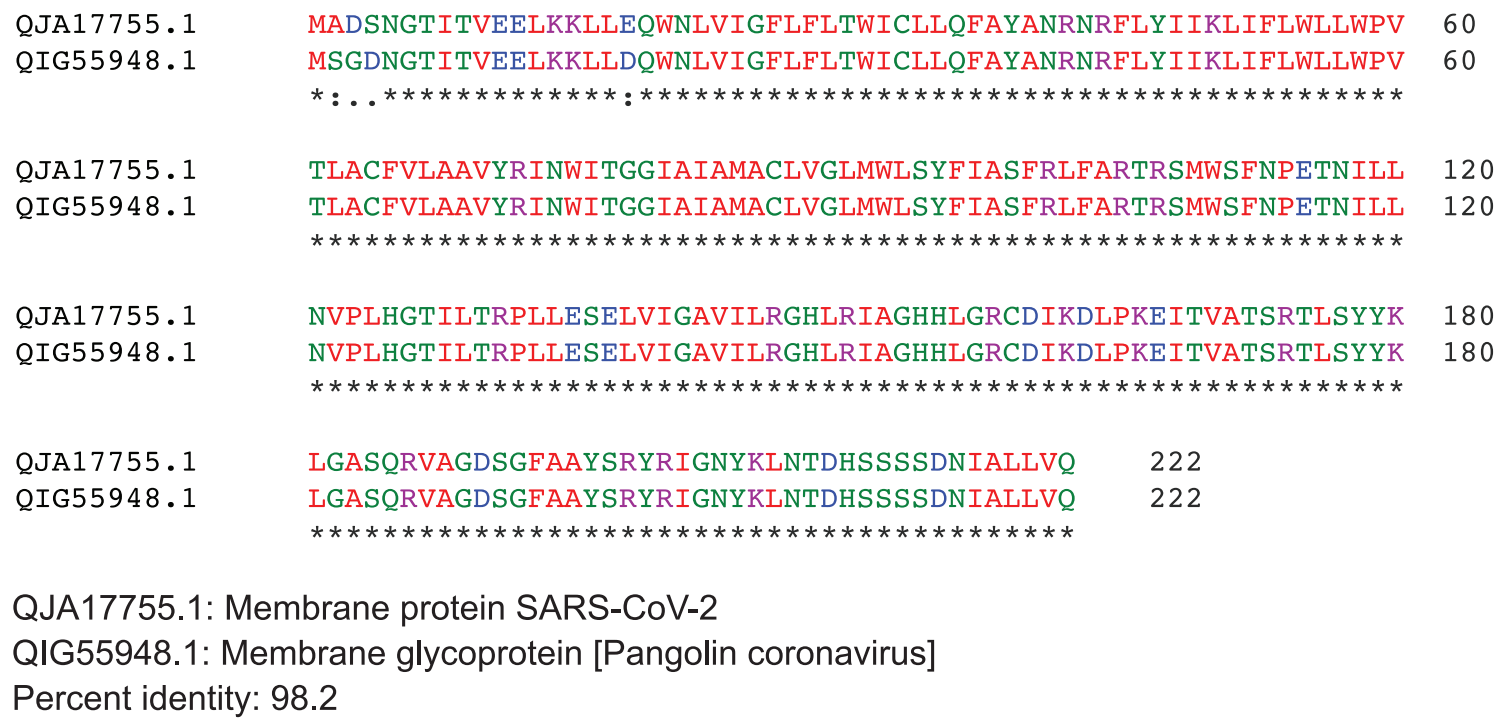

Figure 4B.

\begin{tabular}{|c|c|c|c|}
\hline QJA17755.1 & MADSNGTITVEELKKLLEQWNLVIGFLFLTWICLLQFAYANRN & LYIIKLIFLWLLWPV & 60 \\
\hline AFK10258.1 & $\begin{array}{l}\text {-MADNGTITVEELKQLLEQWNLVIGFLFLAWIMLLQFAYSNRI } \\
\qquad * * * * * * * * * *: * * * * * * * * * * * * * *: * * * * * * * *: * *\end{array}$ & $\begin{array}{l}\operatorname{LYIIKLVFLWLLWPV~} \\
\star * * * * *: * * * * * * * *\end{array}$ & 59 \\
\hline QJA17755.1 & TLACFVLAAVYRINWITGGIAIAMACLVGLMWLSYFIASFRLF & TRSMWSFNPETNILL & 120 \\
\hline AFK10258.1 & $\begin{array}{l}\text { TLACFVLAVVYRINWVTGGIAIAMACIVGLMWLSYFVASFRLF } \\
* * * * * * * . * * * * * *: * * * * * * * * * *: * * * * * * * *: * * * * *\end{array}$ & $\begin{array}{l}\text { TRSMWSFNPETNILL } \\
\star * * * * * * * * * * * * *\end{array}$ & 119 \\
\hline QJA17755.1 & NVPLHGTILTRPLLESELVIGAVILRGHLRIAGHHLGRCDIKD & KEITVATSRTLSYYK & 180 \\
\hline AFK10258.1 & $\begin{array}{l}\text { NVPLRGTIVTRPLMESELVIGAVIIRGHLRMAGHSLGRCDIKD } \\
* * * *: * * *: * * * *: * * * * * * * * * *: * * * * *: * * * * * * * * * * *\end{array}$ & $\begin{array}{l}\text { KEITVATSRTLSYYK } \\
* * * * * * * * * * * * * * *\end{array}$ & 179 \\
\hline QJA17755.1 & LGASQRVAGDSGFAAYSRYRIGNYKLNTDHSSSSDNIALLVQ & 222 & \\
\hline AFK10258.1 & 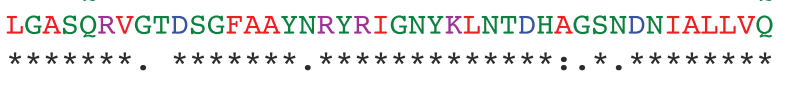 & 221 & \\
\hline
\end{tabular}

QJA17755.1: Membrane protein SARS-CoV-2

AFK10258.1: Membrane protein [SARS coronavirus HKU-39849]

Percent identity: 89.14

Figure 4C. 
CLUSTAL O(1.2.4) multiple sequence alignment

\begin{tabular}{|c|c|c|}
\hline QJA17755.1 & MADSNGTITVEELKKLLEQWNLVIGFLFLTWICLLQFAYANRNRFLYI IKLIFLWLLWPV & 60 \\
\hline \multirow[t]{2}{*}{ AZK15906.1 } & -MSNMTHLTEAQI IAI IKDWNFAWSLIFLLITIVLQYGYPSRSMTVYVFKMFVLWLLWPS & 59 \\
\hline & .. $\quad: * \quad:: \quad:::: * *: . .:: * * \quad: * *: . * \quad * \quad: *:: *:: . * * * * * *$ & \\
\hline QJA17755.1 & TLACFVLAAVYRINWITGGIAIAMACLVGLMWLSYFIASFRLFARTRSMWSFNPETNILL & 120 \\
\hline \multirow[t]{2}{*}{ AZK15906.1 } & SMALSIFSAIYPIDLASQI ISGIVSAVSAMMWISYFVQS IRLFMRTGSWWSFNPETNCLL & 119 \\
\hline & $:: * \quad::: *:_{*}^{*}: \quad: \quad *: \quad:: .: \quad .: * *: * * *: *: * * * * * * * * * * * * * * * *$ & \\
\hline QJA17755.1 & NVPLHGTILTRPLLESELVIGAVILRGHLRIAGHHLGRCDIKDLPKEITVATSRTLSYYK & 180 \\
\hline \multirow[t]{2}{*}{ AZK15906.1 } & NVPIGGTTVVRPLVEDSTSVTAVVTNGHLKMAGMHFGACDYDRLSNEVTVAKPNVLIALK & 179 \\
\hline & 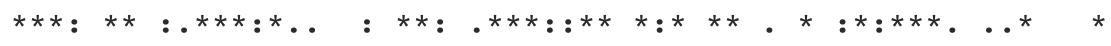 & \\
\hline QJA17755.1 & LGASQRVAGDSGFAAYSRYRIGNYKLNTDHSSSSDNIALLVQ & \\
\hline \multirow[t]{2}{*}{ AZK15906.1 } & MVKRQSYGTNSGVAIYHRYKAGNYRSPPITADI--ELALLRA & \\
\hline & $: \quad * \quad .: * * . * * * *: * * *: \quad: . \quad:: * * *$ & \\
\hline
\end{tabular}

QJA17755.1: Membrane protein SARS-CoV-2

AZK15906.1: Membrane protein [Middle East respiratory syndrome-related coronavirus]

Percent identity: 38.36

Figure 4D.

CLUSTAL O(1.2.4) multiple sequence alignment

WP_113585511.1 QJĀ 17755.1

WP_113585511.1 QJĀ17755.1

WP_113585511.1

QJĀ 17755.1

WP_113585511.1

QJĀ17755.1

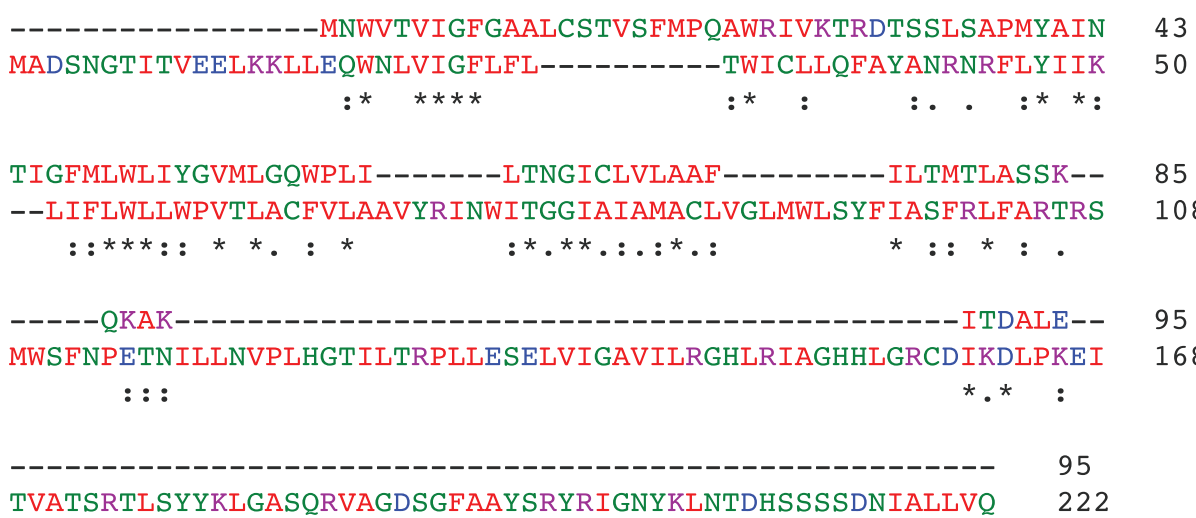

WP_113585511.1: semiSWEET Rhizhobiales

QJA17755.1: Membrane protein SARS-CoV-2

Percent identity: 26.51

Figure 5. Protein sequences were aligned using ClustalW. (A) Comparison of protein sequence of the M protein of SARS-COV-2 with SemiSWEET sugar transporter of Rhizobiales. (B) Comparison of protein sequence of the M protein of SARS-COV-2 with SemiSWEET sugar transporter of Streptococcus pneumoniae. 


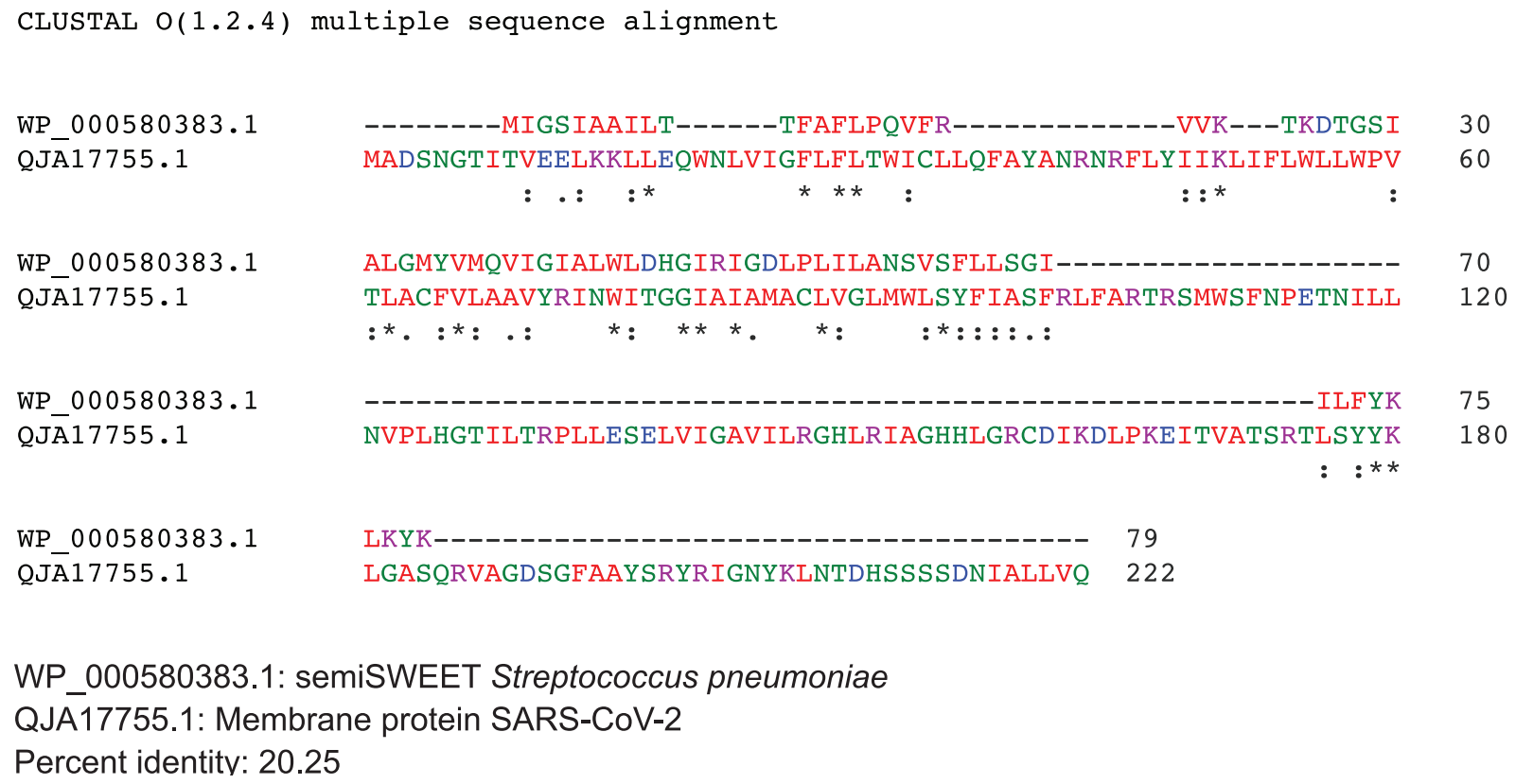

WP_000580383.1: semiSWEET Streptococcus pneumoniae

QJA17755.1: Membrane protein SARS-CoV-2

Percent identity: 20.25

Figure 5B.

used in conjunction with other non-pharmaceutical practices such as social-distancing, and when adoption is nearly universal (nation-wide) and compliance is high [33]. Chu et al [34] support physical distancing of 1 meter or more and hypothesized that contact tracing could reduce the disease transmission.

Understanding the biochemical events of the coronavirus replication cycle may provide a number of attractive targets for drug development [27]. Current strategies involve developing drug and vaccine candidates against the spike $(S)$ protein of the virus. The rationale being that neutralizing antibodies against the S protein prevent uptake of the virus via the human ACE2 receptor [35]. The $\mathrm{S}$ proteins are highly glycosylated making them targets for carbohydrate-binding agents such as lectins. Liu et al [36] showed that the lectin FRIL (Flt3 receptor-interacting lectin), isolated from the hyacinth bean (Lablab purpureus), has anti-SARS-CoV-2 activity. FRIL binds preferentially to complex-type N-glycans and neutralizes viruses that possess complex-type N-glycans on their envelopes. FRIL could effectively neutralize SARS-CoV-2, preventing viral protein production and cytopathic effect in host cells. These data suggest a potential application of FRIL for the prevention and/or treatment of COVID-19 [36]. Identifying drug targets that blunt the activity of the virus may lead to effective treatments for COVID-19.

Viruses are non-living entities, without any organelles and devoid of their own metabolism, though they have the capability to dramatically modify the host cellular metabolism upon entry. Viruses upregulate consumption of glucose and converge on similar metabolic pathways for anabolism [37]. Virus-induced metabolism may provide free nucleotides for rapid viral genome replication, increased amino acid production for rapid virion assembly, and high amounts of ATP for the high energy costs of genome replication and packaging. The mechanism for increased glucose uptake by the virus is still not clearly understood. 
Glucose is the energy source of cells and tissues. Cellular uptake of glucose is a fundamental process for metabolism, growth, and homeostasis. Glucose is a polar molecule that does not readily diffuse across the hydrophobic plasma membrane of cells. Glucose molecules are transported through the glucose transporters that include GLUTs, the sodium-driven glucose symporters SGLTs, STP, and SWEETs [38]. SWEETs are seen in plants and animals. SWEET induction by plant pathogens leads to secretion of sucrose that is used by these microorganisms for nutrition/ reproduction [39].

The bacterial ancestors of SWEET, known as SemiSWEET are the smallest of the sugar transporters and assemble into dimers $[\underline{21}, \underline{40}, \underline{41}]$. In fact, eukaryotic SWEETs consist of 2 SemiSWEET-like units fused via an inversion linker transmembrane helix [17]. The diverse gene neighbors of SemiSWEETs suggest that SemiSWEETs may transport diverse substrates and play several physiological roles in different organisms [17]. The SWEETs and their bacterial homologues, SemiSWEETs, are related to the PQ-loop family, characterized by highly conserved proline and glutamine residues (PQ-loop motif) [41]. The PQ-loop family exhibits diverse activities; they function as cargo receptors in vesicle transport, mediate movement of basic amino acids across lysosomal membranes, and are also involved in phospholipase flippase function [는 $\underline{44}$ ]. As yet, there are no reports of sugar transporters in viruses.

It is not known how SARS-CoV-2 has been successful in spreading all over the world within 3 months of its first reported occurrence in Wuhan, China. Identifying the mechanisms of how viruses alter cellular metabolism and where in the virus life cycle these metabolic changes are necessary will provide an understanding of virus replication needs and potentially provide cellular targets for inhibition of these viruses. In this paper using in silico data analysis we demonstrate that the structure of the membrane $(\mathrm{M})$ glycoprotein of SARS-CoV-2 resembles the SemiSWEET sugar transporter of the prokaryotes.

Clues to the viral metabolism can be understood from the patient population at risk of infection. It is known that people with diabetes are more prone to COVID-19 disease [45]. Recent reports indicate that the SARS-CoV-2 induces diabetes in non-diabetic people [느]. A large case study of COVID-19 patients reported that those with diabetes had a 3-fold higher mortality rate than did those without diabetes ( $7.3 \%$ vs $2.3 \%)$ [ $\underline{47}]$.

Diabetes is a risk factor and is also prevalent in patients infected with other coronaviruses, includ-

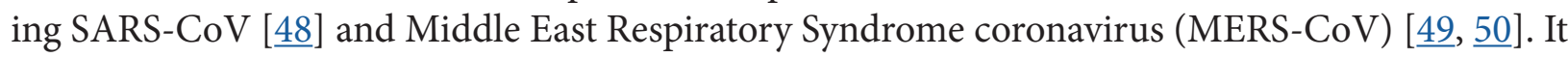
has been demonstrated that SARS coronavirus enters pancreatic islets and damages islets causing acute diabetes [요. As people with diabetes have high glucose, the environment may favor proliferation of viruses. MERS-CoV utilizes dipeptidyl peptidase 4 (DPP4), and modeling of the structure of SARS-CoV-2 spike glycoprotein predicts that it can interact with human DPP4 in addition to ACE2. The protein DPP4 is a ubiquitous membrane-bound aminopeptidase that circulates in plasma; it is multifunctional with roles in nutrition, metabolism, and immune and endocrine systems. DPP4 activity differentially regulates glucose homeostasis and inflammation via its enzymatic activity and nonenzymatic immunomodulatory effects. DPP4 inhibitors, or gliptins are approved for the treatment of type 2 diabetes mellitus [51]. Rhee et al [52] reported that DPP-4 inhibitor is significantly associated with a better clinical outcome of patients with COVID-19.

A virus uses multiple mechanisms for the uptake of glucose. Human cytomegalovirus (HCMV), 
a herpesvirus, induces the sugar transporter, GLUT4 to increase glucose uptake during infection [53]. Whereas, transmissible gastroenteritis virus (TGEV), a coronavirus, induces multiple sugar transporters EGFR, SGLT1, and GLUT2 for glucose uptake [푸]. Rhinoviruses (RVs) are responsible for the majority of upper airway infections, and they enhance the expression of the PI3K-regulated glucose transporter GLUT1; glucose deprivation from medium and via glycolysis inhibition by 2-deoxyglucose impairs viral replication [55].

Sucrose is used for energy metabolism by cells. In addition, sucrose is used for endosome and lysosome maturation, autophagosomes, and also to induce autophagy [ $\underline{56}, \underline{57}]$. Coronaviruses, including SARS and SARS-CoV-2 use endosomes for cellular entry, and they are known to manipulate autophagosomes and autolysosomes for viral dissemination in the cell [ $\underline{58}, \underline{59}]$.

The membrane $(\mathrm{M})$ glycoprotein is the most abundant envelope protein of coronaviruses [60]. In silico analysis demonstrated that M protein of SARS-CoV-2 is $98.6 \%$ similar to the M protein of bat SARS-CoV, maintains 98.2\% homology with pangolin SARS-CoV, and 90\% homology with the M protein of SARS-CoV; whereas, the similarity is only $38 \%$ with the M protein of MERS$\mathrm{CoV}$. Thus, the M protein of SARS-CoV-2 resembles the M protein of bat and pangolin SARS$\mathrm{CoV}$ to a greater extent than MERS-CoV. A recent paper by Zhang et al [61] reported that at the genomic level SARS-CoV- 2 is $96.2 \%$ homologous to bat SARS-CoV (RaTG13) and 91.02\% homologous to pangolin SARS-Co-V.

In silico analysis showed that the $\mathrm{M}$ protein of SARS-CoV-2 resembles the sugar transporter, SWEET. Upon analysis, it was observed that other coronaviruses including SARS-CoV, bat SARS$\mathrm{CoV}$, pangolin SARS-CoV, and MERS-CoV have $\mathrm{M}$ proteins homologous to the sugar transporter SWEET. Further analysis by residue-based structure demonstrated that the protein has the characteristic structure of SemiSWEET, the sugar transporter of prokaryotes. To our knowledge this is the first report of the presence of a sugar transporter-like structure in a virus membrane. It is known that the prokaryotes have diverse sugar transporters. In our analysis, the SARS-CoV-2 sequence of SemiSWEET has no homology to other prokaryotes.

Generally, the enveloped viruses, including SARS-CoV-2, use a 2-step procedure to release their genetic material into the cell: 1) They bind to specific surface receptors of the target cell membrane, and 2) they fuse the viral and cell membranes. This second step may occur at the cell surface or after internalization of the virus particle by endocytosis [62]. Currently, it is not known how the M proteins of the virus are fused to the host cell membrane. If the M proteins are fused to the host cell membrane, they could theoretically function as a sugar transporter.

An advantage of the virus having a sugar transporter in its membrane is that it may influence energy metabolism. How the virus utilizes sugar molecules is unknown. The SARS-CoV-2 virus may use sugar for multiple purposes. The S protein is highly glycosylated. It could be hypothesized that the sugar transporter-like structure of the $M$ protein influences glycosylation of the $S$ protein. In addition, it could be hypothesized that the sugar transporter-like structure of the virus membrane may influence sucrose entry into the endosome, lysosome, or autophagosome that are manipulated by the virus, thereby aiding the virus release into cells. Thus, the presence of a SemiSWEET glucose transporter in the $\mathrm{M}$ protein of the virus may be an efficient mechanism that may induce rapid viral proliferation and immune evasion. 
In many infectious diseases caused by either viruses or bacteria, pathogen glycoproteins play important roles during the infection cycle, ranging from entry to successful intracellular replication and host immune evasion [63]. Toxoplasma gondii is an intracellular bacteria that transitions from acute infection to a chronic infective state in its intermediate host via encystation, which enables the parasite to evade immune detection and clearance. The tissue cyst perimeter is highly and specifically decorated with glycan modifications that are influenced by Toxoplasma nucleotide-sugar transporter (TgNST1). Toxoplasma strains deficient for the TgNST1 gene ( $\Delta \mathrm{nst} 1)$ form cyst-like structures in vitro but no longer interact with lectins, as these strains are deficient in the transport and use of sugars for the biosynthesis of cyst-wall structures. The study demonstrated the role of parasite glycoconjugates in the persistence of Toxoplasma tissue cysts [64].

People with diabetes are at risk of COVID-19 infection which may be due to the high proliferation of the virus because of unmetabolized glucose. A characteristic of some COVID-19 patients is coagulopathy [65]. Anticoagulant therapy with low molecular weight heparin led to a better prognosis in severely ill COVID-19 patients who were associated with high mortality [66]. Platelets, produced by the megakaryocytes of the bone marrow are responsible for blood clotting. Glucose is taken up by the platelets, mediated through the glucose transporters GLUT1 and GLUT3. Lack of glucose transporters in the platelets reduces platelet counts and increases clearance of platelets [67]. Normal glucose levels reduce platelet activation; whereas, hyperglycemia increases platelet glucose metabolism thereby contributing to increased platelet activation and thrombosis in animal models of diabetes [68].

Lungs in some COVID -19 patients are not effectively oxygenating the blood (hypoxia), but these patients feel alert and healthy and hardly gasp for breath. Glucose transport is acutely stimulated by hypoxic conditions, and the response is mediated by enhanced function of the facilitative glucose transporters GLUT $[\underline{69}, \underline{70}]$. Prolonged exposure to hypoxia results in enhanced transcription of the GLUT1 glucose transporter gene, with little or no effect on transcription of other GLUT genes [69].

Several pulmonary disorders are associated with a decrease in alveolar oxygen tension, and alveolar epithelial cells (AEC) exhibit different adaptive mechanisms to cope with oxygen deprivation. Under hypoxia, because of inhibition of oxidative phosphorylation, adenosine triphosphate supply is dependent on the ability of cells to increase anaerobic glycolysis. Hypoxia induces stimulation of $\mathrm{Na}$-independent glucose transport and an increase in 2-deoxyglucose uptake; it also induces the glucose transporter, GLUT1 at both protein and mRNA levels [1] . HIF-1a regulates the activity of glucose transporters, GLUT, that are responsible for glucose uptake. Hypoxia-inducible factors (HIFs) are oxygen-sensitive transcription factors that allow adaptation to hypoxic environments [72]. HIF-1 $\alpha$ reduces acute lung injury by optimizing carbohydrate metabolism in the alveolar epithelium [구이.

An early characteristic of COVID-19 patients is loss of smell. The glucose receptors are expressed in taste receptor cells [74]. Glucose receptors are expressed in the olfactory bulb and changes to the expression of the receptors may influence olfaction [두]. Whereas, Villar et al [ㄷ] demonstrated that glucose removal and the inhibition of glycolysis or oxidative phosphorylation inhibits odor detection.

The data described in this paper are based on in silico analyses; homology models and similarities 
with plant and bacterial glucose transporters are not adequate to assign a role of the $\mathrm{M}$ protein of the virus to specific host comorbidities such as diabetes. Further biological experiments are required to validate the presence and function of the virus membrane sugar transporter.

\section{CONFLICT OF INTEREST}

The author declares no conflict of interest.

\section{ACKNOWLEDGEMENTS}

The author would like to thank the Women's Board of Lankenau for support. The author also acknowledges the Abraham Thomas Foundation for providing the resources for this work.

\section{REFERENCES}

1. Yang X, Zhao J, Yan Q, Zhang S, Wang Y, Li Y. A case of COVID-19 patient with the diarrhea as initial symptom and literature review. Clin Res Hepatol Gastroenterol 2020; pii: S2210-7401(20)30085-1. DOI: 10.1016/j.clinre.2020.03.013.

2. Effenberger M, Grabherr F, Mayr L, Schwaerzler J, Nairz M, Seifert M, Hilbe R, Seiwald S, Scholl-Buergi S, Fritsche G, Bellmann-Weiler R, Weiss G, Müller T, Adolph TE, Tilg H. Faecal calprotectin indicates intestinal inflammation in COVID-19. Gut 2020; pii: gutjnl-2020-321388. DOI: $10.1136 /$ gutjnl-2020-321388.

3. Bai Y, Yao L, Wei T, Tian F, Jin DY, Chen L, Wang M. Presumed asymptomatic carrier transmission of COVID-19. JAMA 2020; 323:1406-1407. DOI: $\underline{10.1001 /}$ jama.2020.2565.

4. Gao Z, Xu Y, Sun C, et al. A systematic review of asymptomatic infections with COVID-19. J Microbiol Immunol Infect 2020; (in press). DOI: 10.1016/j. jmii.2020.05.001.

5. Wang X, Xu W, Hu G, Xia S, Sun Z, Liu Z, Xie Y, Zhang R, Jiang S, Lu L. SARS-CoV-2 infects $\mathrm{T}$ lymphocytes through its spike protein-mediated membrane fusion. Cell Mol Immunol 2020; (in press). DOI: 10.1038/s41423-020-0424-9.

6. Shereen MA, Khan S, Kazmi A, Bashir N, Siddique R. COVID-19 infection: Origin, transmission, and characteristics of human coronaviruses. J Adv Res 2020; 24:91-98. DOI: $10.1016 /$ j.jare.2020.03.005.

7. Chan JF, Kok KH, Zhu Z, Chu H, To KK, Yuan S, Yuen KY. Genomic characterization of the 2019 novel human-pathogenic coronavirus isolated from a patient with atypical pneumonia after visiting Wuhan. Emerg Microbes Infect 2020; 9:221-236. DOI: 10.1080/22221751.2020.1719902.

8. Wrapp D, Wang N, Corbett KS, Goldsmith JA, Hsieh C-L, Abiona O, Graham BS, McLellan JS. Cryo-EM structure of the 2019-nCoV spike in the prefusion conformation. Science 2020; 367: 1260-1263.

9. Amraie R, Napoleon MA, Yin W, et al. CD209L/L-SIGN and CD209/DC-SIGN act as receptors for SARS-CoV-2 and are differentially expressed in lung and kidney epithelial and endothelial cells. Preprint. bioRxiv 2020;2020.06.22.165803. DOI: 
$\underline{10.1101 / 2020.06 .22 .165803 .}$.

10. Mousavizadeh L, Ghasemi S. Genotype and phenotype of COVID-19: Their roles in pathogenesis. J Microbiol Immunol Infect 2020; pii: S1684-1182(20)30082-7.

11. Astuti I, Ysrafil. Severe Acute Respiratory Syndrome Coronavirus 2 (SARS-CoV-2): An overview of viral structure and host response. Diabetes Metab Syndr 2020; 14:407412. DOI: $10.1016 /$ j.dsx.2020.04.020.

12. Bianchi M, Benvenuto D, Giovanetti M, Angeletti S, Ciccozzi M, Pascarella S. SarsCoV-2 envelope and membrane proteins: Structural differences linked to virus characteristics? Biomed Res Int 2020; 2020:4389089. DOI: 10.1155/2020/4389089.

13. Watanabe, Y., Berndsen, Z.T., Raghwani, J. et al. Vulnerabilities in coronavirus glycan shields despite extensive glycosylation. Nat Commun 2020a; 11, 2688.

14. Watanabe Y, Allen JD, Wrapp D, McLellan JS, Crispin M. Site-specific glycan analysis of the SARS-CoV-2 spike. Science 2020b; 369: 330-333.

15. Chen LQ, Hou BH, Lalonde S, Takanaga H, Hartung ML, Qu XQ, Guo WJ, Kim JG, Underwood W, Chaudhuri B, Chermak D, Antony G, White FF, Somerville SC, Mudgett MB, Frommer WB. Sugar transporters for intercellular exchange and nutrition of pathogens. Nature 2010; 468:527-532. DOI: $\underline{10.1038 / \text { nature09606. }}$

16. Feng L, Frommer WB. Structure and function of semiSWEET and SWEET sugar transporters. Trends Biochem Sci 2015; 40: 480-486. DOI: 10.1016/j.tibs.2015.05.005.

17. Jia B, Hao L, Xuan YH, Jeon CO. New insight into the diversity of semiSWEET sugar transporters and the homologs in prokaryotes. Front Genet 2018; 9:180. DOI: $10.3389 /$ fgene.2018.00180.

18. Jeena GS, Kumar S, Shukla RK. Structure, evolution and diverse physiological roles of SWEET sugar transporters in plants. Plant Mol Biol 2019; 100:351-365. DOI: $\underline{10.1007 /}$ s11103-019-00872-4.

19. Chen LQ. SWEET sugar transporters for phloem transport and pathogen nutrition. New Phytol 2014; 201:1150-1155. DOI: 10.1111/nph.12445.

20. Han L, Zhu Y, Liu M, Zhou Y, Lu G, Lan L, Wang X, Zhao Y, Zhang XC. Molecular mechanisms of substrate recognition and transport by the AtSWEET 13 sugar transporter. Proc Natl Acad Sci USA 2017; 114:10089-10094. DOI: 10.1073/ pnas.1709241114.

21. Xuan YH, Hu YB, Chen LQ, Sosso D, Ducat DC, Hou BH, Frommer WB. Functional role of oligomerization for bacterial and plant SWEET sugar transporter family. Proc Natl Acad Sci USA 2013; 110: E3685-94. DOI: 10.1073/pnas.1311244110.

22. Waterhouse A, Bertoni M, Bienert S, Studer G, Tauriello G, Gumienny R, Heer FT, de Beer TAP, Rempfer C, Bordoli L, Lepore R, Schwede T. SWISS-MODEL: homology modelling of protein structures and complexes. Nucleic Acids Res 2018; 46(W1):W296-W303. DOI: 10.1093/nar/gky427.

23. Skrabanek L, Campagne F, Weinstein H. Building protein diagrams on the web with the residue-based diagram editor RbDe. Nucleic Acids Res 2003; 31: 3856-3858. DOI: 10.1093/nar/gkg552. 
24. Omasits U, Ahrens CH, Müller S, Wollscheid B. Protter: interactive protein feature visualization and integration with experimental proteomic data. Bioinformatics 2014; 30:884-6. DOI: 10.1093/bioinformatics/btt607.

25. Thompson JD, Higgins DG, Gibson TJ. CLUSTAL W: improving the sensitivity of progressive multiple sequence alignment through sequence weighting, position-specific gap penalties and weight matrix choice. Nucleic Acids Res 1994; 22:4673-80. DOI: $10.1093 / \mathrm{nar} / 22.22 .4673$.

26. Schwede T, Kopp J, Guex N, Peitsch MC. SWISS-MODEL: An automated protein homology-modeling server. Nucleic Acids Res 2003; 31: 3381-3385. DOI: 10.1093/nar/ gkg520.

27. Ghosh AK, Brindisi M, Shahabi D, Chapman ME, Mesecar AD. Drug development and medicinal chemistry efforts toward SARS-Coronavirus and Covid-19 therapeutics. Chem Med Chem 2020; 15: 907-932. DOI: 10.1002/cmdc.202000223.

28. Castagnoli R, Votto M, Licari A, Brambilla I, Bruno R, Perlini S, Rovida F, Baldanti F, Marseglia GL. Severe Acute Respiratory Syndrome Coronavirus 2 (SARS-CoV-2) infection in children and adolescents: A systematic review. JAMA Pediatr 2020; (in press). DOI: $\underline{10.1001 / \text { jamapediatrics.2020.1467. }}$

29. Ngonghala CN, Iboi E, Eikenberry S, Scotch M, MacIntyre CR, Bonds MH, Gumel AB. Mathematical assessment of the impact of non-pharmaceutical interventions on

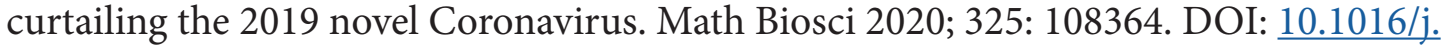
mbs.2020.108364.

30. Howard J, Huang A, Li Z, Tufekci Z, Zdimal V, van der Westhuizen H, von Delft A, Price A, Fridman L, Tang L, Tang V, Watson GL, Bax CE, Shaikh R, Questier F, Hernandez D, Chu LF, Ramirez CM, Rimoin AW. Face masks against COVID-19: An evidence review. Preprints 2020, 2020040203. DOI: 10.20944/preprints202004.0203.v3.

31. Jayaweera M, Perera H, Gunawardana B, Manatunge J. Transmission of COVID-19 virus by droplets and aerosols: A critical review on the unresolved dichotomy. Environ Res 2020; 188:109819. DOI: 10.1016/j.envres.2020.109819.

32. Bahl P, Doolan C, de Silva C, Chughtai AA, Bourouiba L, MacIntyre CR. Airborne or droplet precautions for health workers treating COVID-19? J Infect Dis 2020 Apr 16: jiaa189. DOI: 10.1093/infdis/jiaa189.

33. Eikenberry SE, Mancuso M, Iboi E, Phan T, Eikenberry K, Kuang Y, Kostelich E, Gumel AB. To mask or not to mask: Modeling the potential for face mask use by the general public to curtail the COVID-19 pandemic. Infect Dis Model 2020; 5: 293-308. DOI: $10.1016 /$ j.idm.2020.04.001.

34. Chu DK, Akl EA, Duda S, Solo K, Yaacoub S, Schünemann HJ; COVID-19 Systematic Urgent Review Group Effort (SURGE) study authors. Physical distancing, face masks, and eye protection to prevent person-to-person transmission of SARS-CoV-2 and COVID-19: a systematic review and meta-analysis. Lancet 2020; 395: 1973-1987. DOI: 10.1016/S0140-6736(20)31142-9.

35. Le T, Andreadakis Z, Kumar A, Gómez Román R, Tollefsen S, Saville M, Mayhew S. 
The COVID-19 vaccine development landscape. Nat Rev Drug Discov 2020; 19:305306.

36. Liu YM, Shahed-Al-Mahmud M, Chen X, et al. A carbohydrate-binding protein from the edible Lablab beans effectively blocks the infections of influenza viruses and SARSCoV-2. Cell Rep 2020; 32:108016. DOI: 10.1016/j.celrep.2020.108016.

37. Thaker SK, Ch'ng J, Christofk HR. Viral hijacking of cellular metabolism. BMC Biol 2019; 17:59. DOI: 10.1186/s12915-019-0678-9.

38. Deng D, Yan N. GLUT, SGLT, and SWEET: Structural and mechanistic investigations of the glucose transporters. Protein Sci 2016; 25: 546-558. DOI: 10.1002/pro.2858.

39. Bezrutczyk M, Yang J, Eom JS, Prior M, Sosso D, Hartwig T, Szurek B, Oliva R, Vera-Cruz C, White FF, Yang B, Frommer WB. Sugar flux and signaling in plant-microbe interactions. Plant J 2018; 93:675-685. DOI: 10.1111/tpj.13775.

40. Chen LQ, Cheung LS, Feng L, Tanner W, Frommer WB. Transport of sugars. Annu Rev Biochem 2015; 84: 865-894. DOI: 10.1146/annurev-biochem-060614-033904.

41. Lee Y, Nishizawa T, Yamashita K, Ishitani R, Nureki O. Structural basis for the facilitative diffusion mechanism by SemiSWEET transporter. Nat Commun 2015; 6:6112. DOI: $10.1038 /$ ncomms7112.

42. Saudek V. Cystinosin, MPDU1, SWEETs and KDELR belong to a well-defined protein family with putative function of cargo receptors involved in vesicle trafficking. PLoS One. 2012; 7(2):e30876. DOI: 10.1371/journal.pone.0030876.

43. Yamamoto T, Fujimura-Kamada, K, Shioji E, Suzuki R, Tanaka K. Cfs1p, a novel membrane protein in the PQ-loop family, is involved in phospholipid flippase functions in Yeast. G3 2017; 7: 179-192. DOI: 10.1534/g3.116.035238.

44. Kawano-Kawada M, Manabe K, Ichimura H, Kimura T, Harada Y, Ikeda K, Tanaka S, Kakinuma Y, Sekito T. A PQ-loop protein Ypq2 is involved in the exchange of arginine and histidine across the vacuolar membrane of Saccharomyces cerevisiae. Sci Rep 2019; 9:15018. DOI: 10.1038/s41598-019-51531-Z.

45. Bornstein SR, Rubino F. et al. Practical recommendations for the management of diabetes in patients with COVID-19. Lancet Diabetes Endocrinol 2020; 8: 546-550. DOI: 10.1016/S2213-8587(20)30152-2.

46. Iacobellis G, Penaherrera CA, Bermudez LE, Bernal Mizrachi E. Admission hyperglycemia and radiological findings of SARS-CoV2 in patients with and without diabetes. Diabetes Res Clin Pract 2020; 164:108185. DOI: 10.1016/j.diabres.2020.108185.

47. Wu Z, McGoogan JM. Characteristics of and important lessons from the coronavirus disease 2019 (COVID-19) outbreak in China: Summary of a report of 72314 cases from the Chinese Center for Disease Control and Prevention. JAMA 2020; 323:12391242. DOI: $10.1001 /$ jama.2020.2648.

48. Yang JK, Lin SS, Ji XJ, Guo LM. Binding of SARS coronavirus to its receptor damages islets and causes acute diabetes. Acta Diabetol 2010; 47:193-199. DOI: $\underline{10.1007 /}$ s00592-009-0109-4.

49. Badawi A, Ryoo SG. Prevalence of comorbidities in the Middle East respiratory syn- 
drome coronavirus (MERS-CoV): a systematic review and meta-analysis. Int J Infect Dis 2016; 49:129-33. DOI: 10.1016/j.ijid.2016.06.015.

50. Nassar MS, Bakhrebah MA, Meo SA, Alsuabeyl MS, Zaher WA. Middle East Respiratory Syndrome Coronavirus (MERS-CoV) infection: epidemiology, pathogenesis and clinical characteristics. Eur Rev Med Pharmacol Sci 2018; 22:4956-4961. DOI: 10.26355/eurrev $201808 \quad 15635$.

51. Bassendine MF, Bridge SH, McCaughan GW, Gorrell MD. COVID-19 and comorbidities: A role for dipeptidyl peptidase 4 (DPP4) in disease severity? J. Diabetes 2020;10.1111/1753-0407.13052. DOI: 10.1111/1753-0407.13052.

52. Rhee SY, Lee J, Nam H, Kyoung D-S, Kim DJ. Effects of a DPP-4 inhibitor and RAS blockade on clinical outcomes of patients with diabetes and COVID-19. medRxiv 2020.05.20.20108555. DOI: $10.1101 / 2020.05 .20 .20108555$.

53. Yu Y, Clippinger AJ, Pierciey FJ Jr, Alwine JC. Viruses and metabolism: alterations of glucose and glutamine metabolism mediated by human cytomegalovirus. Adv Virus Res 2011; 80:49-67. DOI: 10.1016/B978-0-12-385987-7.00003-8.

54. Dai L, Hu WW, Xia L, Xia M, Yang Q. Transmissible gastroenteritis virus infection enhances SGLT1 and GLUT2 expression to increase glucose uptake. PLoS One 2016; 11(11):e0165585. DOI: 10.1371/journal.pone.0165585.

55. Gualdoni GA, Mayer KA, Kapsch AM, Kreuzberg K, Puck A, Kienzl P, Oberndorfer F, Frühwirth K, Winkler S, Blaas D, Zlabinger GJ, Stöckl J. Rhinovirus induces an anabolic reprogramming in host cell metabolism essential for viral replication. Proc Natl Acad Sci USA 2018; 115: E7158-E7165. DOI: 10.1073/pnas.1800525115.

56. Higuchi T, Nishikawa J, Inoue H. Sucrose induces vesicle accumulation and autophagy. J Cell Biochem 2015; 116: 609-617. DOI: 10.1002/jcb.25012.

57. Zhao YG, Zhang H. Autophagosome maturation: An epic journey from the ER to lysosomes. J Cell Biol 2019; 218: 757-770. DOI: 10.1083/jcb.201810099.

58. Burkard C, Verheije MH, Wicht O, van Kasteren SI, van Kuppeveld FJ, Haagmans BL, Pelkmans L, Rottier PJ, Bosch BJ, de Haan CA. Coronavirus cell entry occurs through the endo-/lysosomal pathway in a proteolysis-dependent manner. PLoS Pathog 2014; 10(11):e1004502. DOI: 10.1371/journal.ppat.1004502.

59. Yang N, Shen HM. Targeting the endocytic pathway and autophagy process as a novel therapeutic strategy in COVID-19. Int J Biol Sci 2020; 16:1724-1731. DOI: $\underline{10.7150 /}$ ijbs. 45498 .

60. de Haan CA, Smeets M, Vernooij F, Vennema H, Rottier PJ. Mapping of the coronavirus membrane protein domains involved in interaction with the spike protein. J Virol 1999; 73: 7441-7452.

61. Zhang T, Wu Q, Zhang Z. Probable pangolin origin of SARS-CoV-2 associated with the COVID-19 outbreak. Curr Biol 2020; 30:1346-1351.e2. DOI: 10.1016/j. cub.2020.03.022.

62. White JM, Whittaker GR. Fusion of enveloped viruses in endosomes. Traffic 2016; 17: 593-614. DOI: 10.1111/tra.12389. 
63. Yap SSL, Nguyen-Khuong T, Rudd PM, Alonso S. Dengue virus glycosylation: What do we know? Front Microbiol 2017; 8:1415. DOI: 10.3389/fmicb.2017.01415.

64. Caffaro CE, Koshy AA, Liu L, Zeiner GM, Hirschberg CB, Boothroyd JC. A nucleotide sugar transporter involved in glycosylation of the Toxoplasma tissue cyst wall is required for efficient persistence of bradyzoites. PLoS Pathog 2013; 9(5): e1003331. DOI: 10.1371/journal.ppat.1003331.

65. Tang N, Li D, Wang X, Sun Z. Abnormal coagulation parameters are associated with poor prognosis in patients with novel coronavirus pneumonia. J Thromb Haemost 2020; 18: 844-847. DOI: $10.1111 /$ jth.14768.

66. Tang N, Bai H, Chen X, Gong J, Li D, Sun Z. Anticoagulant treatment is associated with decreased mortality in severe coronavirus disease 2019 patients with coagulopathy. J Thromb Haemost 2020; 18: 1094-1099. DOI: 10.1111/jth.14817.

67. Fidler TP, Campbell RA, Funari T, Dunne N, Balderas Angeles E, Middleton EA, Chaudhuri D, Weyrich AS, Abel ED. Deletion of GLUT1 and GLUT3 reveals multiple roles for glucose metabolism in platelet and megakaryocyte function. Cell Rep 2017; 21:1705. DOI: 10.1016/j.celrep.2017.06.083.

68. Fidler TP, Marti A, Gerth K, Middleton EA, Campbell RA, Rondina MT, Weyrich AS, Abel ED. Glucose metabolism is required for platelet hyperactivation in a murine model of type 1 diabetes. Diabetes 2019; 68: 932-938. DOI: $10.2337 / \mathrm{db} 18-0981$.

69. Zhang JZ, Behrooz A, Ismail-Beigi F. Regulation of glucose transport by hypoxia. Am. J Kidney Dis 1999; 34: 189-202. DOI: 10.1016/s0272-6386(99)70131-9.

70. Wood IS, Wang B, Lorente-Cebrián S, Trayhurn P. Hypoxia increases expression of selective facilitative glucose transporters (GLUT) and 2-deoxy-D-glucose uptake in human adipocytes. Biochem Biophys Res Commun 2007; 361: 468-73. DOI: $\underline{10.1016 / \mathrm{j}}$. bbrc.2007.07.032.

71. Ouiddir A, Planès C, Fernandes I, VanHesse A, Clerici C. Hypoxia upregulates activity and expression of the glucose transporter GLUT1 in alveolar epithelial cells. Am. J. Respir. Cell Mol Biol 1999; 21: 710-718. DOI: 10.1165/ajrcmb.21.6.3751.

72. Sadlecki P, Bodnar M, Grabiec M, Marszalek A, Walentowicz P, Sokup A, Zegarska J, Walentowicz-Sadlecka M. The role of Hypoxia-inducible factor-1 $\alpha$, glucose transporter-1, (GLUT-1) and carbon anhydrase IX in endometrial cancer patients. Biomed Res Int 2014; 2014:616850. DOI: 10.1155/2014/616850.

73. Eckle T, Brodsky K, Bonney M, Packard T, Han J, Borchers CH, et al. (2013) HIF1A reduces acute lung injury by optimizing carbohydrate metabolism in the alveolar epithelium. PLoS Biol 11(9): e1001665. DOI: 10.1371/journal.pbio.1001665.

74. Merigo F, Benati D, Cristofoletti M, Osculati F, Sbarbati A. Glucose transporters are expressed in taste receptor cells. J Anat 2011; 219:243-252. DOI: 10.1111/j.14697580.2011.01385.x.

75. Al Koborssy D, Palouzier-Paulignan B, Salem R, Thevenet M, Romestaing C, Julliard AK. Cellular and molecular cues of glucose sensing in the rat olfactory bulb. Front Neurosci 2014; 8:333. DOI: 10.3389/fnins.2014.00333. 
76. Villar PS, Delgado R, Vergara C, Reyes JG, Bacigalupo J. Energy requirements of odor transduction in the chemosensory cilia of olfactory sensory neurons rely on oxidative phosphorylation and glycolytic processing of extracellular glucose. J Neurosci 2017; 37: 5736-5743. DOI: 10.1523/JNEUROSCI.2640-16.2017.

\section{FOOTNOTES}

Submitted April 28, 2020 | Accepted June 16, 2020 | Published October 19, 2020

\section{COPYRIGHT}

Copyright (C) 2020 Pathogens and Immunity. This is an open-access article distributed under the terms of the Creative Commons Attribution 4.0 International License. 